Family Profile No. 14, 2020

\title{
Fatherhood in the U.S.: The Decoupling of Marriage and Childbearing
}

Author: Lisa Carlson

The rising age at first marriage (FP-19-06; FP-20-01) combined with the growth in nonmarital childbearing (FP-18-24; FP-19-28) means many men are already fathers when they marry for the first time (FP-18-24, FP-19-06, FP-19-28, and FP-20-01). This family profile extends an earlier Family Profile (FP-12-09) on the decoupling of marriage and fatherhood in the U.S by examining the number of biological children men have prior to entering their first marriage. Using four waves of the National Survey of Family Growth (2002, 2006-2010, 2013-2015, and 2015-2017), this profile compares fatherhood at the time of marriage across three marriage cohorts: men who first married in the 1990s, men who first married in the 2000s, and men who married between 2010 and 2017 with an emphasis on variation by educational attainment and race/ethnicity.

Men's Number of Children by Marriage Cohort

- Most men in each marriage cohort entered their first marital union with no biological children. However, compared to men who first married in the 1990s, men in the 2000s and the 2010s marriage cohorts had smaller shares childless $(75 \%$ and $74 \%$ in the latter cohorts versus $82 \%$ in the former cohort).

- Of those with children, the most common scenario across all three marriage cohorts was to have only one child prior to marriage.

- The proportion of men who began their first marriage with more than one child almost doubled between the 1990s cohort and the 2000s cohort (from $6 \%$ to $11 \%$ ) but then decreased very slightly for the 2010-2017 marriage cohort (10\%).

Figure 1. Men's Number of Children by Marriage Cohort

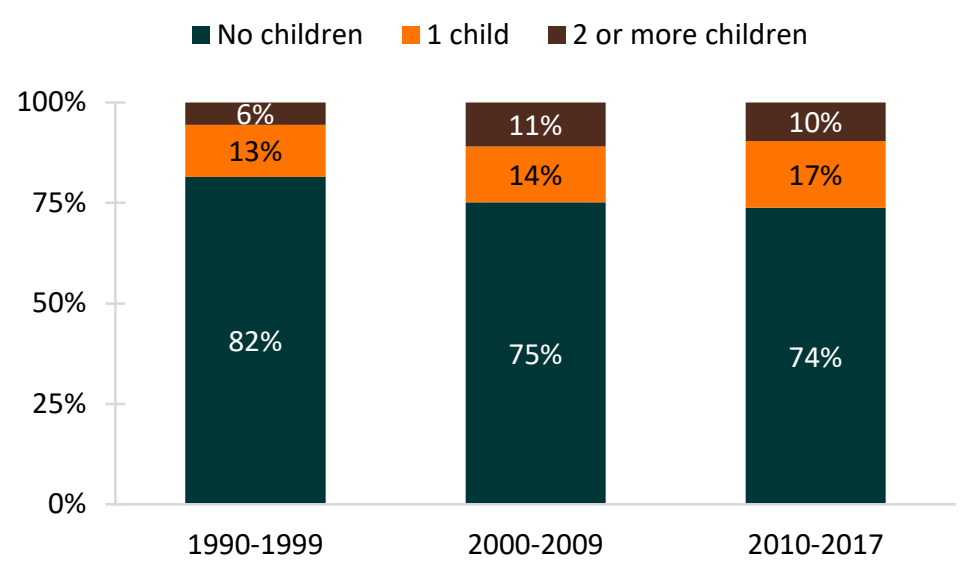

Source: NCFMR analyses of NSFG 2002, 2006-2010, 2013-2015, and 2015-2017 Male Data files

\section{Men's Number of Children by Marriage Cohort and Race/Ethnicity}

- The patterns of fatherhood at marriage entry varied markedly by race and ethnicity.

$\circ$ For Hispanic men, the trend was rather stable. Roughly one-third of Hispanic men were fathers when entering a first marriage in the 1990s with the two most recent cohorts at $37 \%$ and $36 \%$, respectively.

- For White men, the share entering first marriage with a child nearly doubled over time, rising from $12 \%$ for the $1990 \mathrm{~s}$ cohort to $23 \%$ for the 2010 s cohort.

- For Black men, the proportion with at least one child at the start of their first marriage increased between the 1990s and 2000 s cohorts (44\% to $54 \%$ ) but then plummeted for the most recent cohort (36\%).

- The racial and ethnic gap in the share of fathers who had a child at first marriage entry has narrowed over time.

Figure 2. Men's Number of Children by Marriage Cohort and Race/Ethnicity

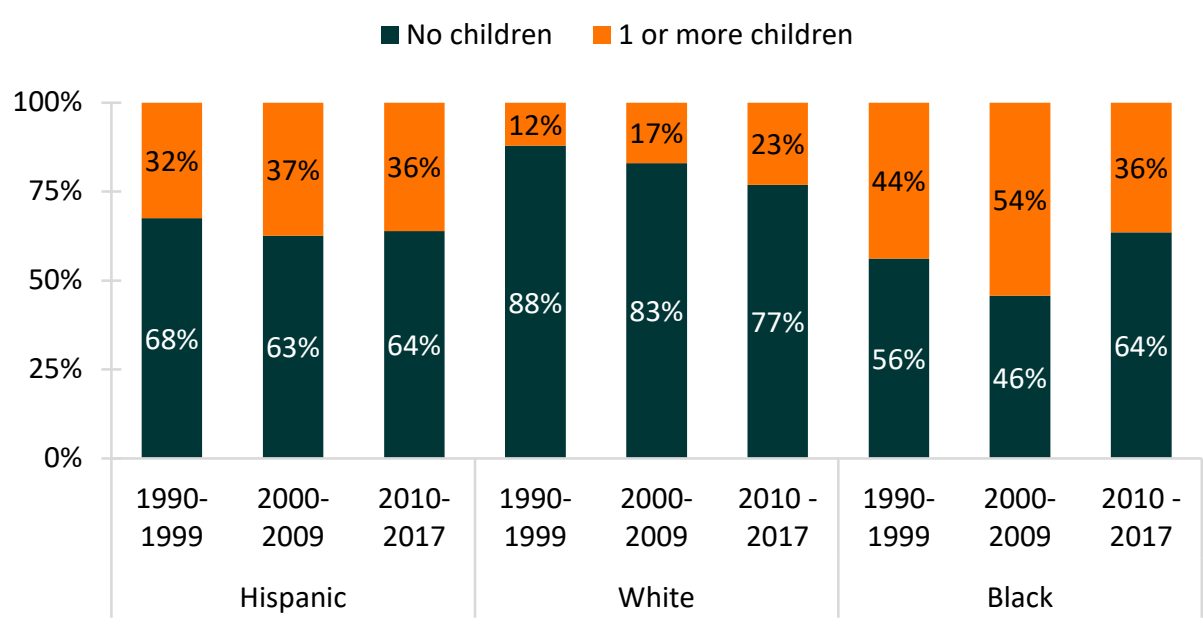


Men's Number of Children by Marriage Cohort and Educational Attainment

- Generally, the share of men entering a first marriage with at least one child had increased across marriage cohort regardless of educational attainment.

- The exception is found among men with some college education, where the share of men who entered marriage with at least one child was lower among men who married in the 2010 s compared with men who married in the 2000 s ( $25 \%$ compared to $28 \%$ ).

- Regardless of marriage cohort, the proportion of men who entered their first marriage with children declined with educational attainment.

- More than two-thirds of recently married men without a high school diploma were already fathers in contrast to $39 \%$ of high school graduates.

- A quarter of recently married men with some college entered marriage with children compared to $7 \%$ of men with a bachelor's degree.

Figure 3. Men's Number of Children by Marriage Cohort and Educational Attainment

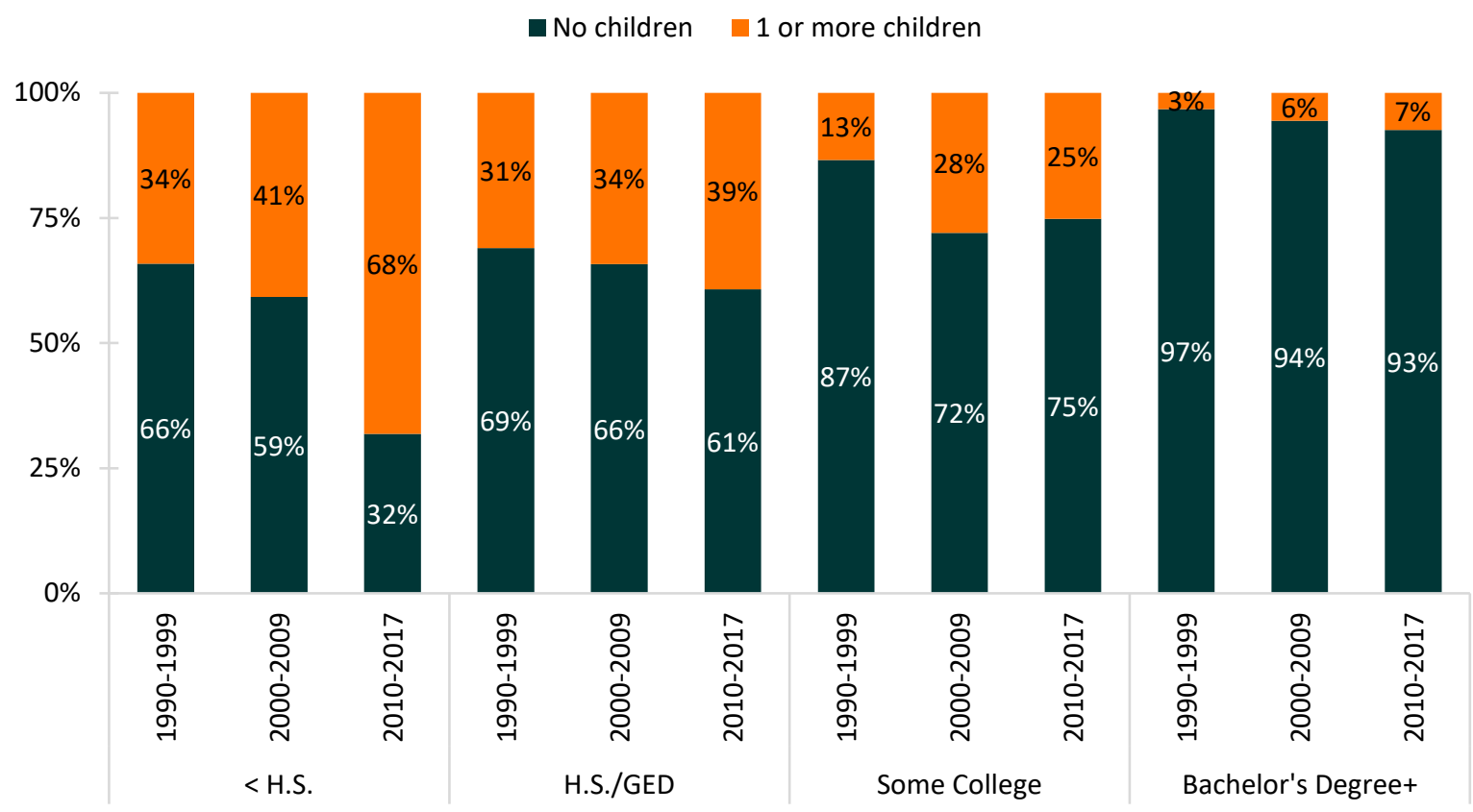

Source: NCFMR analyses of NSFG 2002, 2006-2010, 2013-2015, and 2015-2017 Male Data files

\section{References:}

Hemez, P. (2018). Young adulthood: Sequencing of union experiences relative to first birth. Family Profiles, FP-18-24. Bowling Green, OH: National Center for Family \& Marriage Research. https://doi.org/10.25035/ncfmr/fp-18-24

Payne, Krista (2012). Fatherhood in the U.S.: The decoupling of marriage and childbearing. Family Profiles, FP-12-09. Bowling Green, OH: National Center for Family \& Marriage Research. Retrieved from http://ncfmr.bgsu.edu/pdf/family_profiles/file112105.pdf

Payne, K. K. (2019). Median age at first marriage, 2017. Family Profiles, FP-19-06. Bowling Green, OH: National Center for Family \& Marriage Research. https://doi.org/10.25035/ncfmr/fp-19-06

Schweizer, V. J. (2019). 30 Years of change in men's entry into fatherhood, 1987-2017. Family Profiles, FP-19-28. Bowling Green, OH: National Center for Family \& Marriage Research. https://doi.org/10.25035/ncfmr/fp-19-28

Schweizer, V. (2020). First marriage rate in the U.S., 2018. Family Profiles, FP-20-01. Bowling Green, OH: National Center for Family \& Marriage Research. https://doi.org/10.25035/ncfmr/fp-20-01

\section{Suggested Citation:}

Carlson, L. (2020). Fatherhood in the U.S.: The decoupling of marriage and childbearing. Family Profiles, FP-20-14. Bowling Green, $\mathrm{OH}$ : National Center for Family \& Marriage Research. https://doi.org/10.25035/ncfmr/fp-20-14

BGSU. Fational Center for http://www.bgsu.edu/ncfmr ncfmr@bgsu.edu

(419) 372-3119 